Erratum

\title{
Erratum to "Modulation of Vasodilator Response via the Nitric Oxide Pathway after Acute Methyl Mercury Chloride Exposure in Rats"
}

\author{
S. Omanwar, ${ }^{1}$ B. Saidullah, ${ }^{1}$ K. Ravi, ${ }^{2}$ and M. Fahim ${ }^{3}$ \\ ${ }^{1}$ School of Sciences, Indira Gandhi National Open University, New Delhi 110068, India \\ ${ }^{2}$ Department of Physiology, V.P. Chest Institute, University of Delhi, New Delhi 110007, India \\ ${ }^{3}$ Jamia Hamdard University, New Delhi 110062, India \\ Correspondence should be addressed to S. Omanwar; swatiomanwar@gmail.com \\ Received 5 September 2013; Accepted 24 October 2013; Published 30 January 2014
}

Copyright (c) 2014 S. Omanwar et al. This is an open access article distributed under the Creative Commons Attribution License, which permits unrestricted use, distribution, and reproduction in any medium, provided the original work is properly cited.

In the original paper, there was an error in Figure 2(c). Figures 2(b) and 2(c) were the same, and here we provide the right form of Figure 2(c). 


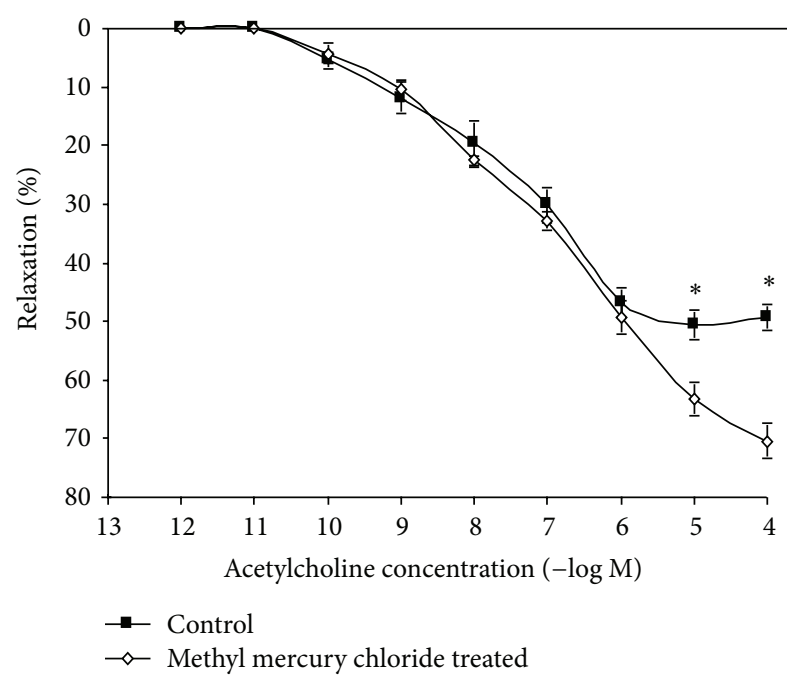

(a)

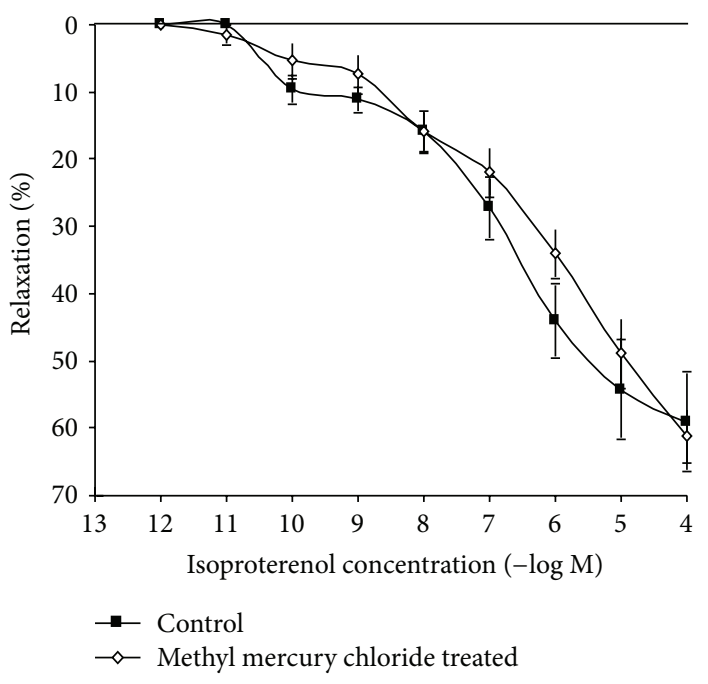

(b)

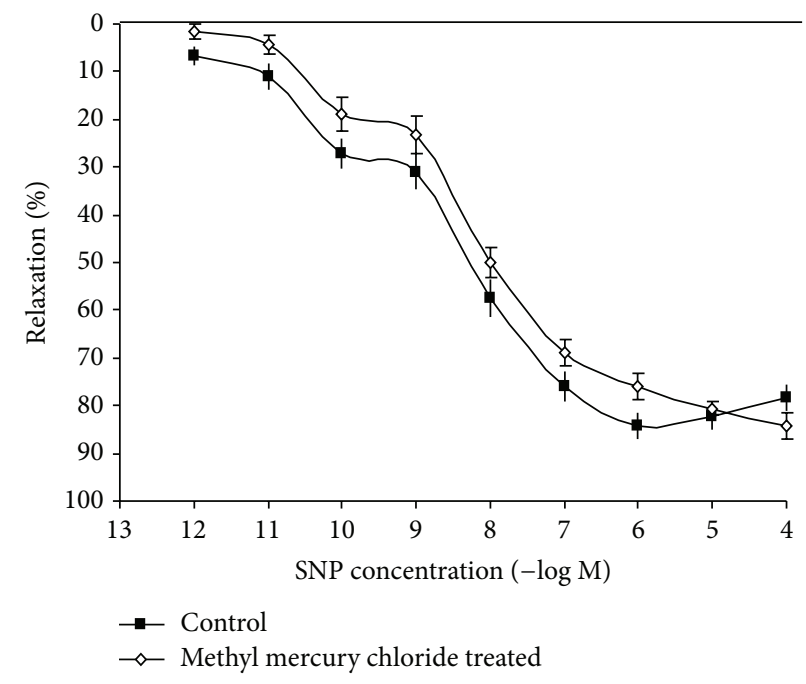

(c)

(c)

FIGURE 2: Effect of methyl mercury chloride treatment on the vascular relaxation response to acetylcholine, isoproterenol, and sodium nitroprusside. Concentration-response curves to (a) acetylcholine (ACh), (b) isoproterenol (IP), and (c) sodium nitroprusside (SNP) in the aortas of rats untreated, treated with methyl mercury chloride $(n=10)$ precontracted with PE. The results (mean \pm SEM) are expressed as percentage of the response to PE. $t$-test, ${ }^{*} P<0.05$. 

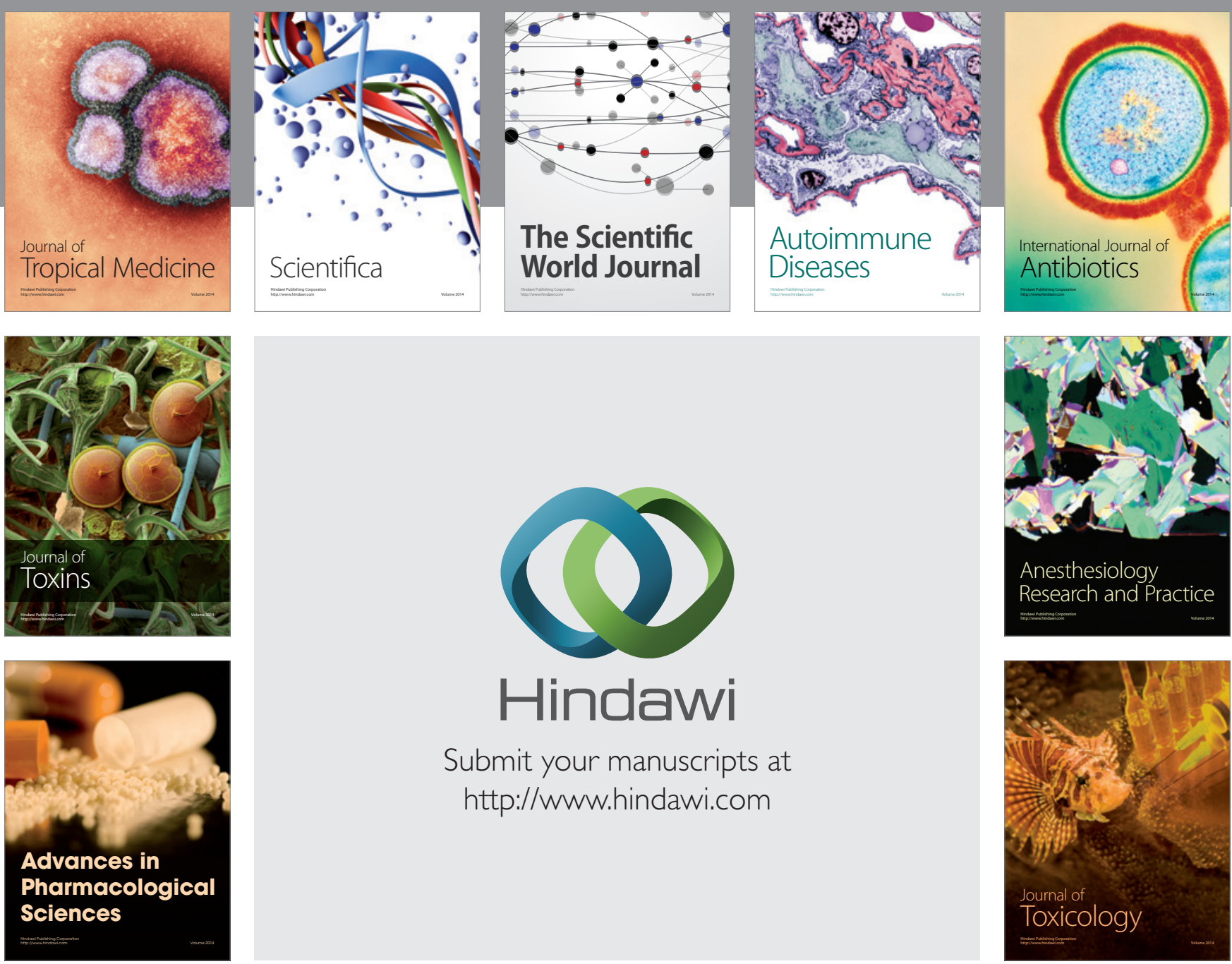

\section{Hindawi}

Submit your manuscripts at

http://www.hindawi.com
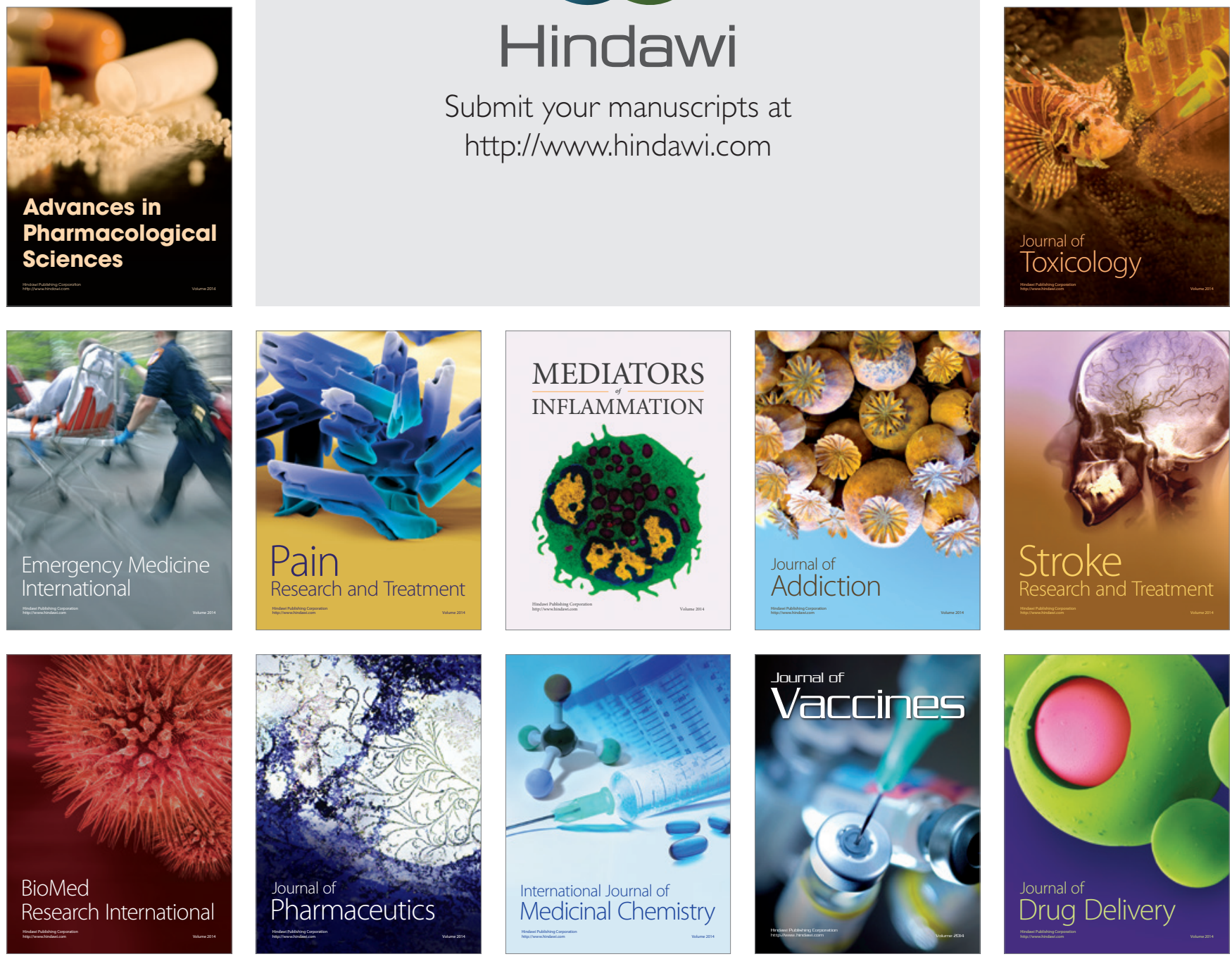